Provided for non-commercial research and education use. Not for reproduction, distribution or commercial use.

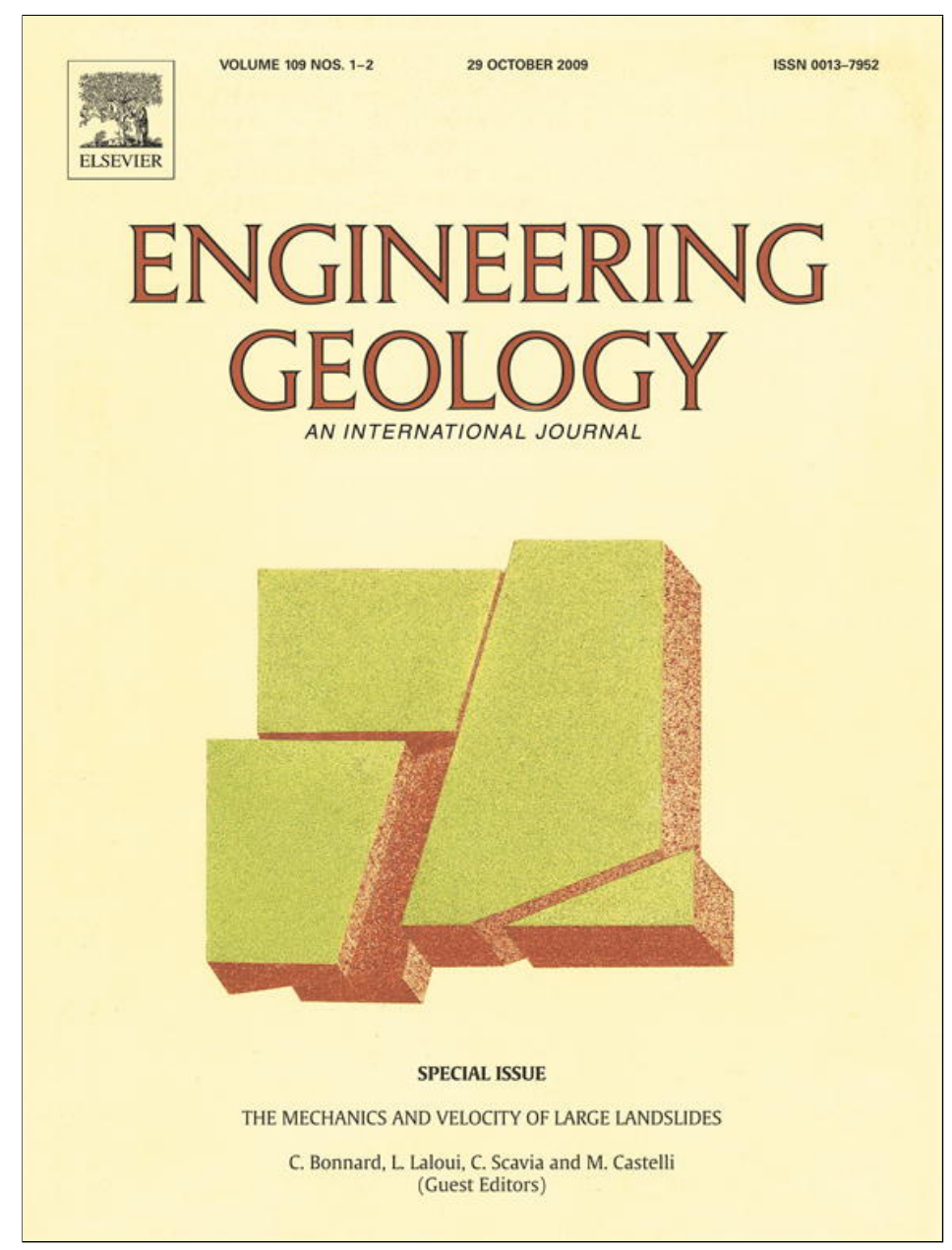

This article appeared in a journal published by Elsevier. The attached copy is furnished to the author for internal non-commercial research and education use, including for instruction at the authors institution and sharing with colleagues.

Other uses, including reproduction and distribution, or selling or licensing copies, or posting to personal, institutional or third party websites are prohibited.

In most cases authors are permitted to post their version of the article (e.g. in Word or Tex form) to their personal website or institutional repository. Authors requiring further information regarding Elsevier's archiving and manuscript policies are encouraged to visit:

http://www.elsevier.com/copyright 


\title{
Identification of mechanisms for landslide type initiation of debris flows
}

\author{
G. Klubertanz, L. Laloui *, L. Vulliet \\ Soil Mechanics Laboratory (LMS), Ecole Polytechnique Fédérale de Lausanne (EPFL), Station 18, CH-1015 Lausanne, Switzerland
}

\section{A R T I C L E I N F O}

\section{Article history:}

Received 8 December 2007

Received in revised form 3 June 2009

Accepted 25 June 2009

Available online 7 July 2009

\section{Keywords:}

Debris flow initiation

Numerical modelling

Coupled hydro-mechanical model

Finite elements

Parametric study

\begin{abstract}
A B S T R A C T
The modelling of debris flow initiation in slopes is addressed in this paper. First, possible factors governing debris flow initiation are established. Then, a coupled hydro-mechanical model for deformable porous media with two pore fluids that is used to assess the problem of the debris flow initiation in slopes is briefly outlined. Various ways to identify failure and to approach the transition of the failed mass into a debris flow are discussed in the framework of small strain theory and elasto-plastic behaviour. A parametric study was carried out to evaluate the relative importance of the most commonly cited parameters that are assumed to influence debris flow initiation. It was found that the slope angle is of minor importance in the development of slope instability under loading due to internal water supply. Transient behaviour was found to be decisive, and some critical combinations of water supply over time yielded situations that were likely to encourage the onset of debris flow. The significant role of permeability as a function of the degree of saturation in relation to the water supply is demonstrated. The proposed three-phase model is shown to be an adequate and promising way to address debris flow initiation.

(c) 2009 Elsevier B.V. All rights reserved.
\end{abstract}

\section{Introduction}

This paper is a contribution to the improved understanding of debris flow initiation mechanisms and the prediction of the failure location and initial debris volume. This information is essential in the planning of preventative measures. The chosen methodology makes use of numerical modelling with advanced geomechanical physics. In order to develop a promising modelling strategy, accurate hypotheses and suggestions concerning debris flow initiation, a brief review is presented in the following sections.

\subsection{Sources of information}

\subsubsection{Eye witnesses}

Few people have ever claimed to have actually witnessed debris flow initiation; however, in spite of the generally unfavourable observation conditions (initiations most often take place in mountainous regions during stormy periods) it has been possible to observe debris flow initiation directly on slopes on some occasions. Johnson and Rodine (1984) report some of these observations. In most cases, it was observed that small parts of a slope failed first (on the order of cubic meters), and the debris flow grew slowly while incorporating other failed masses (see also Morton and Cambell, 1973). Only in very few cases was it observed that the mass constituting the debris flow failed as a whole (Williams and Guy, 1973).

\footnotetext{
* Corresponding author. Tel.: +41 21 6932315; fax: +41 216934153. E-mail address: lyesse.laloui@epfl.ch (L. Laloui).
}

\subsubsection{Case studies}

Many authors have conducted studies evaluating old debris flow traces (Table 1). It is, however, extremely difficult to detect common features among all these events. This is primarily because of variations in the circumstances of the occurrence of the debris flows and in the material in question and also because of the differing focuses of the reports.

\subsubsection{Laboratory experiments}

Some laboratory experiments concerning debris flow initiation or similar mechanisms have been reported in the literature. Eckersly (1990) conducted experiments on the failure of a coal pile and induced failure by raising the water table. Experimental studies concerning debris flow initiation have been conducted at the ETH Zürich by Tognacca and Bezzola (1997, Tognacca, 1999), and experiments close to real scale have been carried out by Iverson (1997). In both cases, failure was provoked by adding water to an unsaturated soil mass.

\subsection{Possible factors influencing debris flow initiation}

\subsubsection{Topography}

One of the most-cited factors for debris flow initiation is topography. One requirement for initiation is the availability of material that can be mobilized. Depending on the circumstances, this can be a fine-grained material, such as sand or gravel (Ellen and Fleming, 1987) or, as is often observed in the Swiss Alps, a coarser material with a wide grain size distribution (Rösli and Schindler, 1990).

The initiation zone of debris flows is often found on slopes with an angle of more than $15^{\circ}$ (Takahashi, 1991). There are numerous other 
Table 1

Selected case studies.

\begin{tabular}{lll}
\hline Authors & Year & Study \\
\hline Studies covering numerous cases & $(1984)$ & 137 events in Europe \\
Eisenbacher & $(1990)$ & 9 events in northern USA \\
Buchanan and Savigny & $(1993)$ & 449 events on Queen Charlot Island \\
Fannin and Rollenson & $(1993)$ & French alps \\
Blijenberg & $(1993)$ & 49 alpine valleys \\
Rickenmann and Zimmermann & $(1995)$ & 82 events in Switzerland \\
Rickenmann & $(1997)$ & 54 events in California \\
Wieczorek et al. & & \\
Studies focusing on one case & $(1970)$ & State College, Pennsylvania, USA \\
Johnson and Rahn & $(1984)$ & Mt. Usu, Japan \\
Sassa & $(1995)$ & Nant du Pissot, VD, Switzerland \\
Service hydrologique et geologique \\
$\quad$ national & & \\
Rovina & $(1995)$ & Rittigraben, VS, Switzerland \\
Zimmermann & $(1994)$ & Dorfbach Randa, Switzerland \\
\hline
\end{tabular}

proposals to identify typical topographic features of debris flow initiation locations, e.g., Buchanan and Savigny (1990), Fannin and Rollenson (1993), Johnson and Sitar (1990), Costa (1984), Johnson and Rahn (1970), Takahashi (1980) or Statham (1976). All of these studies observe different features in the topography of debris flow initiation sites. Summarizing all these observations, one realizes that topography seems to be an important feature in the initiation mechanism, but there is no unique, sufficient and necessary pattern for debris flow initiation.

\subsubsection{Material parameters}

Material parameters are also often studied in the context of debris flow initiation. Many authors tend to establish correlations between certain parameters and the occurrence of debris flows, e.g., Takahashi (1991), who focused on the shear strength of the material, or Ellen and Fleming (1987), who chose steady state and critical state parameters, as did Anderson and Sitar (1995) and Lade (1993). Yet, intrinsic parameters, such as density and porosity (Blijenberg, 1993) or the plasticity index (Ellen and Fleming 1987) are also mentioned. Of course, grain size distribution is a quantity analyzed in virtually all field studies, but the numerous works do not point to common features for comparable debris flows and locations.

\subsubsection{State of stress}

Some authors consider the initial state of stress in the affected slope (Sassa et al.,1980). In this context, preconsolidation pressure is also cited as an influential factor (Anderson and Sitar, 1991; Budhu, 1995).

\subsubsection{Water}

Water acts in numerous ways on the stability of slopes. Its influence has been shown experimentally (Eckersly, 1990) and numerically (Reid and Iverson, 1992). Local inhomogeneities (Haneberg, 1995) or highly permeable layers (Iverson and Reid, 1992) can amplify its destabilizing effect. Some authors claim that the increase in pore water pressure due to rainfall is a direct cause of debris flow initiation (Reid et al., 1988; Rösli and Schindler, 1990; Haneberg, 1991; Cojean, 1994). There are other mechanisms that are mentioned, mainly in relation to the time behaviour of some water-dependent quantities, such as water level changes, rainfall intensity or runoff (Takahashi, 1981; Okimura, 1983; Suwa, 1989).

\subsubsection{Others}

There are additional factors mentioned in the literature that are assumed to trigger debris flow initiation. Some of these are sudden loading due to some event (Sassa, 1988; Harp and Jibson, 1996; Cojean and Staub, 1998) or the transformation of existing slides in debris flows for no apparent cause (Johnson and Rahn, 1970; Lee et al., 1988). In high mountainous regions, permafrost may play a role in destabilizing slopes during melting (Zimmermann and Häberli, 1992; Mortara et al., 1995; Dysli, 1998). As these cases seem to be rather rare and not to represent typical debris flow initiation mechanisms, but rather appear to be related to physical processes, such as dynamics or phase change, they are disregarded in the remainder of the document.

\subsection{Summary}

In order to make predictions of practical value, one has to answer the following questions:

$$
\begin{aligned}
& >\text { where will the debris flow occur? } \\
& >\text { when will it occur? } \\
& >\text { what will be the affected volume? }
\end{aligned}
$$

Any model for the prediction of debris flow initiation should at least in principal be able to answer these questions. Models that are unable to provide that information will be of limited usefulness. It would be advantageous to construct a model in a way that accounts for all the above-mentioned features and possible factors or excludes them based on physical reasons. This requires large model flexibility and implies as few a-priori assumptions as possible.

A deterministic mechanical model based on continuum mechanics would meet these requirements if it incorporated pore fluid and nonsaturation effects, which is shown in this paper.

\section{Mathematical model}

A mathematical formulation of a coupled hydro-mechanical model that will serve as a numerical approach to study debris flow initiation is briefly presented. The relations and their application in the present context are extensively discussed in Klubertanz (1999) and Klubertanz et al. (1997, 2000). This model is based on continuum mechanics and considers the soil as a deformable porous medium filled with two immiscible pore fluids (water and gas); the mass and momentum balance equations form a highly coupled, non-linear system. A brief description of this multiphase model is given below. When water fills all the voids, the mixture is called saturated. Otherwise it is unsaturated.

The model is based on the equilibrium and mass conservation of each constituent (e.g., Hassanizadeh and Gray (1979a,b), Schrefler et al., 1990).

\subsection{General formulation}

\subsubsection{Momentum balance}

The momentum balance for the three-phase mixture reads, neglecting inertia terms:

$\nabla \cdot \sigma+\rho g=0$

where $\sigma$ is the (total) stress tensor, $\boldsymbol{g}$ the gravity vector and $\rho$ the density of the mixture with $\rho=(1-n) \rho^{\mathrm{s}}+n S^{\mathrm{w}} \rho^{\mathrm{w}}+n S^{\mathrm{a}} \rho^{\mathrm{a}}$. Note that here $\rho^{\mathrm{s}}$, $\rho^{\mathrm{w}}$ and $\rho^{\mathrm{a}}$ are the densities of solid, water and air, respectively. $S^{\mathrm{w}}$ and $S^{\mathrm{a}}$ are the degrees of water and air saturation defined as the volume ratio of water and air, respectively, divided by the total pore volume of the control volume. Note that, throughout this paper, quantities related to the solid, water or gas phases are denoted by the superscripts $s, w$ and $a$, respectively. Furthermore, $\nabla \cdot$ denotes the divergence operator.

The total stress is expressed as:

$\sigma=-S^{\mathrm{w}} p^{\mathrm{w}}-\left(1-S^{\mathrm{w}}\right) p^{\mathrm{a}}+\sigma^{\prime}$

where $\sigma^{\prime}$ is the effective stress and $p^{\mathrm{w}}$ and $p^{\mathrm{a}}$ are the pore water and the pore air pressures, respectively. This relation corresponds to the Bishop effective stress (Bishop, 1959; Schrefler, 1984) that is most suitable for the modelling of the behaviour of soils under saturated and unsaturated conditions (Nuth and Laloui, 2008; Laloui and Nuth, 
2009). It could be derived from thermodynamic considerations (mixture theory) with the following hypotheses (Laloui et al., 2003): incompressible solid grains as well as water phase, compressible gas phase, perfect fluids and the phase separation concept.

\subsubsection{Mass conservation}

The combined mass balance equations for water/solid or air/solid using Darcy's Law for both fluid phases:

$$
\begin{aligned}
& \left(\frac{n}{S^{\mathrm{w}}} \frac{\partial S^{\mathrm{w}}}{\partial s}+\frac{n}{\rho^{\mathrm{w}}} \frac{\partial \rho^{\mathrm{w}}}{\partial p^{\mathrm{w}}}\right) \frac{\partial p^{\mathrm{w}}}{\partial t}-\frac{n}{S^{\mathrm{w}}} \frac{\partial S^{\mathrm{w}}}{\partial s} \frac{\partial p^{\mathrm{a}}}{\partial t}+ \\
& \nabla \cdot v^{\mathrm{s}}+\nabla \cdot\left(\frac{k_{\mathrm{rw}} K}{\mu^{\mathrm{w}}}\left(\nabla p^{\mathrm{w}}-\rho^{\mathrm{w}} \boldsymbol{g}\right)\right)=0
\end{aligned}
$$

for the water/solid mass balance and

$$
\begin{aligned}
& \left(\frac{n}{1-S^{\mathrm{w}}} \frac{\partial S^{\mathrm{w}}}{\partial s}+\frac{n}{\rho^{\mathrm{a}}} \frac{\partial \rho^{\mathrm{a}}}{\partial p^{\mathrm{a}}}\right) \frac{\partial p^{\mathrm{a}}}{\partial t}-\frac{n}{1-S^{\mathrm{w}}} \frac{\partial S^{\mathrm{w}}}{\partial s} \frac{\partial p^{\mathrm{w}}}{\partial t}+ \\
& \nabla \cdot v^{\mathrm{s}}+\nabla \cdot\left(\frac{k_{\mathrm{ra}} K}{\mu^{\mathrm{a}}}\left(\nabla p^{\mathrm{a}}-\rho^{\mathrm{a} g}\right)\right)=0
\end{aligned}
$$

for the air/solid mass balance.

Here $n$ denotes the porosity. The relative permeability $k_{\mathrm{rw}}$ of water is assumed to be a function of the degree of water saturation and porosity with the relative permeability of air $k_{\mathrm{ra}}$ considered as a function of the degree of saturation only (Seker, 1983). $K$ is the intrinsic permeability, and $\mu^{\mathrm{w}}$ and $\mu^{\mathrm{a}}$ are the dynamic viscosity of the water and air phases, respectively. $v^{s}$ is the (Lagrangian) velocity of the solid skeleton and $s$ denotes the matrix suction $\left(s=p^{\mathrm{a}}-p^{\mathrm{w}}\right)$. A non-linear capillary pressure saturation relation is used (Seker, 1983).

\subsubsection{Discretised system}

The finite element formulation for the discrete approximation of the partial differential equations governing the problem (Eqs. (1), (3) and (4)) is then introduced. Using a standard Galerkin procedure and an explicit Euler method for discretisation, one finds the following system of equations:

$$
\begin{aligned}
& \mathbf{L} d u_{n+1}+\mathbf{L}^{\mathrm{w}} d p_{n+1}^{\mathrm{w}}+\mathbf{L}^{\mathrm{a}} d p_{n+1}^{\mathrm{a}}=\boldsymbol{F}_{n+1}-\nabla \cdot \mathbf{T}_{n}-\mathbf{L}^{\mathrm{w}} p_{n}^{\mathrm{w}}-\mathbf{L}^{\mathrm{a}} p_{n}^{\mathrm{a}} \\
& \mathbf{L}^{\mathrm{wT}} d u_{n+1}+\left(\mathbf{M}^{\mathrm{w}}+\Delta t \mathbf{H}^{\mathrm{w}}\right) d p_{n+1}^{\mathrm{w}}+\mathbf{N}^{\mathrm{wa}} d p_{n+1}^{\mathrm{a}}=-\Delta t \mathbf{H}^{\mathrm{w}} p_{n}^{\mathrm{w}}+\boldsymbol{F}_{n+1}^{\mathrm{w}} \\
& \mathbf{L}^{\mathrm{aT}} d u_{n+1}+\left(\mathbf{M}^{\mathrm{a}}+\Delta t \mathbf{H}^{\mathrm{a}}\right) d p_{n+1}^{\mathrm{a}}+\mathbf{N}^{\mathrm{aw}} d p_{n+1}^{\mathrm{w}}=-\Delta t \mathbf{H}^{\mathrm{a}} p_{n}^{a}+\boldsymbol{F}_{n+1}^{\mathrm{a}}
\end{aligned}
$$

$\mathbf{L}$ is the stiffness matrix, $\mathbf{L}^{\mathrm{w}}$ and $\mathbf{L}^{\mathrm{a}}$ the liquid and gas flow matrices, and $\boldsymbol{F}$, $\boldsymbol{F}^{\mathrm{w}}$, and $\boldsymbol{F}^{\mathrm{a}}$ are the mechanical, water and air loading vectors, respectively. $\mathbf{T}$ is the Cauchy stress tensor. The other matrices are given in Appendix A.

The system of Eq. (5) is evaluated in a two-step approach. Based on the results at time step $n$, the system of equations is solved and the matrices are updated using the new values for stresses and pressures. The solution at time step $n+1$ is found using the updated matrices. This approach has proven to be stable and accurate for reasonably large values of the time step $\nabla t$. Convergence behaviour is generally good.

\subsubsection{Constitutive model for unsaturated soils}

The constitutive behaviour of soils is modelled using the Hiss- $\delta_{1}$ model, which was initially developed for saturated soils (Desai et al. 1991 ) and extended to unsaturated soils Hiss- $\delta_{1 \text { unsat }}$ (Geiser et al., 2000) to include the effects of suction on mechanical behaviour. The model has two yield limits. The mechanical yield surface is formulated as:

$\boldsymbol{F}_{1} \equiv \frac{J_{2 \mathrm{D}}}{p_{\text {ref }}^{2}}-\left[-\alpha_{m}\left(\frac{J_{1}^{\prime}+R}{p_{\text {ref }}}\right)^{m}+\gamma\left(\frac{J_{1}^{\prime}+R}{p_{\text {ref }}}\right)^{2}\right] \boldsymbol{F}_{\mathrm{s}}$

where $\boldsymbol{F}_{\mathrm{S}}=\left[1-\beta \cdot\left(\sqrt{27} / 2 \cdot J_{3 \mathrm{D}} \cdot J_{2 \mathrm{D}}^{-3 / 2}\right)\right]^{-0.5} \cdot J^{\prime}{ }_{1}$ is the first invariant of the effective stress tensor $\left(=3\left(p-p^{\mathrm{w}}\right)\right.$, with $p$ the mean total stress, $p=\operatorname{tr} \sigma, J_{2 \mathrm{D}}$ and $J_{3 \mathrm{D}}$ are the second and the third invariant of the deviatoric stress, respectively. $p_{\text {ref }}$ is the atmospheric pressure and $\gamma$ and $\beta$ are the final parameters related to the friction angle and the critical pressure. $\alpha_{m}$ is the hardening parameter related to the volumetric plastic deformation and suction. $m$ is the phase change parameter related to the state of stress at which transition from compaction to dilation occurs or at which the change in the volume vanishes. $R$ is a bonding stress parameter related to cohesion; it increases with suction (as the cohesion increases with the suction) (Fig. 1, area 3):

$\begin{cases}R(s)=R(0) & \text { for } s<s_{\mathrm{e}} \\ R(s)=R(0)+r \sqrt{s} & \text { for } s \geq s_{\mathrm{e}}\end{cases}$

$s_{\mathrm{e}}$ is the suction air entry value, and $r$ is a material parameter.

For hydric behaviour, the second yield limit $\boldsymbol{F}_{2}$ permits a description of the behaviour of the mean effective stress $\left(p^{\prime}=t r \sigma^{\prime}\right)$ suction $(s)$ plane:

$\boldsymbol{F}_{2} \equiv-\left[-\alpha_{\mathrm{h}}\left(\frac{3 s}{p_{\text {ref }}}\right)^{m}+\gamma\left(\frac{3 s}{p_{\text {ref }}}\right)^{2}\right] F_{\mathrm{s}} s<s_{\mathrm{e}}$

where $\alpha_{\mathrm{h}}$ is a hardening parameter.

\section{Recognizing debris flow initiation}

Before applying the presented mathematical model, some aspects of the simulation of the debris flow initiation are discussed in the following sections.

\subsection{Stability criterion}

All finite element small strain formulations become invalid after the onset of failure and the development of large displacements. Thus, the question of whether a given slope will actually fail numerically is not easy to answer in the context of the proposed approach, since failure cannot be calculated directly. Nevertheless, some indicators show first the identification of zones that are likely to fail and second the decision of whether there is a chance that the failed mass will develop into a debris flow.

Possible instability indicators of failure are:

- Large shear stresses: shear stress failure is a classic failure mode in soils. Stability (equilibrium) can be checked using a plastic criterion.

- Extensive displacements: intuitively one tends to identify the zone of failure with the zone of largest displacements.

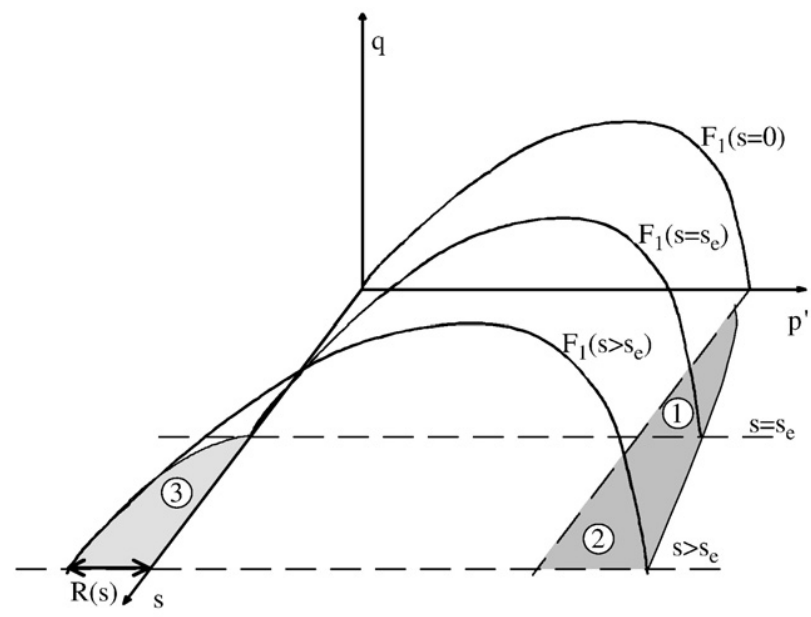

Fig. 1. Mechanical yield limit in the shear stress $\left(q \equiv J_{2 \mathrm{D}}\right)$ mean effective stress $\left(p^{\prime}=\operatorname{tr} \sigma^{\prime}\right)$ and suction (s) space. 
- Vanishing effective stress: a rising pore water pressure will reduce the effective stress in the soil. Zones with full liquefaction are identified as having failed.

- Large plastic strains: the occurrence of plastic strains does not necessarily mean that the affected part of the slope will fail. There is a rather large zone of moderate deformation between the onset of plastic deformation and actual failure.

- Approaching the critical state line: when water is supplied to the soil, the state of stress at a given point will change at a constant shear stress, and the first invariant of the effective stress tensor will decrease towards the critical state line.

- Numerical instability: the numerical divergence of the calculation may indicate the physical instability of the slope.

- Value of the yield surface: the numerical value of the yield function may serve as an indication for the safety margin in the slope.

Which of these criteria apply, alone or in combination with others, must be decided based on comparisons of computed results with laboratory experiments and field observations.

\subsection{Transition to debris flow}

A failing mass does not necessarily develop into a debris flow. It is possible that it will develop into a slow-moving landslide and will stop after a short distance.

Mechanisms of transition from failing mass to debris flow are generally unknown. Ellen and Fleming (1987) report three types of mobilization and note that mobilization generally occurs at the toe of the slope. Iverson et al. (1997) conducted large-scale experiments and concluded that contractive soil behaviour plays a major role in debris flow mobilization. Three possible mechanisms are assumed to control the transition from failing mass to debris flow: strain-induced change of pore water pressure, supply of runoff water and erosion.

- Strain-induced change of pore-water pressure: Depending on the initial conditions, the soil may undergo two types of volumetric changes: contraction or expansion (dilation). Very loose soils tend to undergo a decrease in pore volume, while dense soils show expansive behaviour. This will have consequences on the pore water pressure under saturated and unsaturated conditions, since the deformation rate will be large compared to typical flow velocities in the soil; the behaviour can be considered to be undrained. Consequently, pore pressures will depend directly on the volumetric strain of the soil, which implies that pore pressure will increase rapidly in contractive soils. This will not be the case in expansive (dilatant) soils. Sassa (1984) claims that this rise in pore pressure is the main cause for fast-moving debris flows. Another mechanism that may lead to contractive behaviour is structural collapse. This can be observed for loose, unsaturated soils when their degree of saturation is increased (wetting path, cf. Sassa, 1984). This can be modelled by the proposed approach (see subsequent parametric studies).

- Supply of runoff water: Johnson and Rahn (1970) report observations concerning the transition of a landslide to a debris flow that involves the incorporation (mixing) of surface water (runoff) into the soil body. The debris flow occurs once a sufficient quantity of water has been incorporated. In this case, the pore water content may be an indicator of the transition towards debris flow. Threshold indicators are, however, still uncertain (a possible candidate is the liquid limit). The modelling of this phenomenon is a problem of rapid, multi-phase non-Newtonian fluid flow and cannot be considered using a small strain approach.

- Erosion: In some cases heavy erosion causes debris flows due to the accumulation of the eroded material (see e.g. Meyer and Wells, 1997, or Griffiths et al., 1997). Simulating erosion necessitates the consideration of events which take place outside the original calculation domain, and this cannot be treated with the present approach.

\section{Parametric studies}

The coupled hydromechanical model has been applied to a slope stability problem in order to evaluate the influence of the abovementioned parameters on potential debris flow initiation situations.

\subsection{Scenario}

\subsubsection{Geometry}

Test calculations were made using two geometries: an infinite slope (geometry 1, Fig. 2) and a more realistic slope geometry with two horizontal plateaus (geometry 2, Fig. 3).

The origin of the Cartesian coordinate system is located in the lower left corner of the calculation domain; points 1 to 3 are sampling points for results. The slope angle, $\alpha$, in geometry 1 varies and takes the values $20^{\circ}, 25^{\circ}$ (standard case) and $30^{\circ}$.

\subsubsection{Boundary conditions}

Boundary conditions are given in Fig. 4. To keep the hydraulic boundary conditions simple, a water supply in the slope body is assumed to be present, and it is realized as imposed flow $q_{\mathrm{w}}$ (geometries 1 and 2) or constant pore water pressure $p^{\mathrm{w}}$ (only for geometry 1). This corresponds to a high permeability layer or a fissure in the soil or bedrock, which is a rather common scenario in theories concerned with debris flow initiation (e.g., Johnson and Rahn (1970), Lee et al. (1988) or Iverson and Reid (1992)).

For geometry 1, the water supply is a square between the points $(11 / 4.5)$ and (14/6.5), and for geometry 2 it is between (11/5.7) and (19/6.7). The temporal evolution of the influx is given in Fig. 5.

The water level is imposed $7 \mathrm{~m}$ below the surface at the left and right boundaries for geometry 1 , and for geometry $2,5 \mathrm{~m}$ on the left (uphill) side and $4 \mathrm{~m}$ below the surface on the right (downhill) side, if not stated otherwise. In the case of geometry 1 this corresponds to a slope-parallel water table, while for geometry 2 it leads to a highly unsaturated zone in

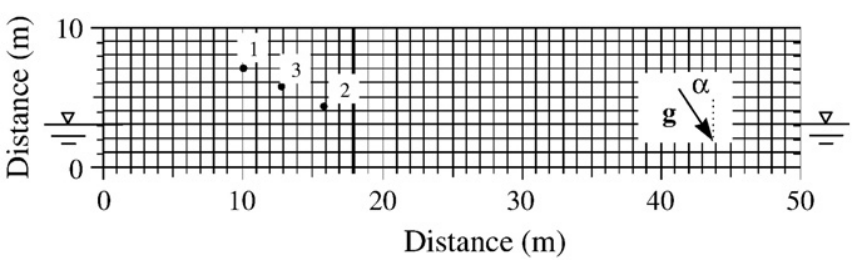

Fig. 2. Geometry 1 and finite elements mesh (note inclination of gravity vector $\mathbf{g}$ ).

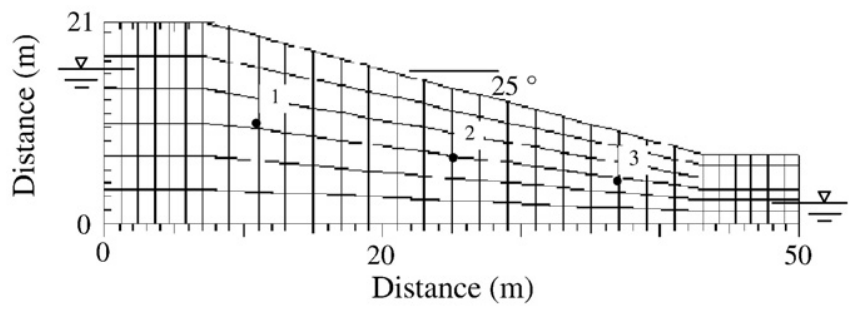

Fig. 3. Geometry 2 and finite elements mesh.
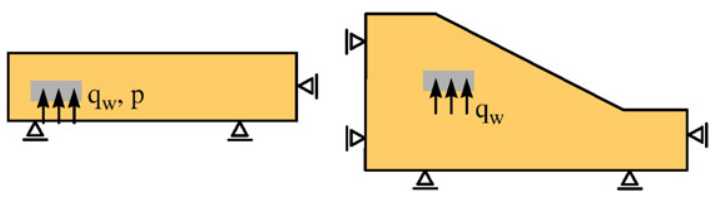

Fig. 4. Boundary conditions. 


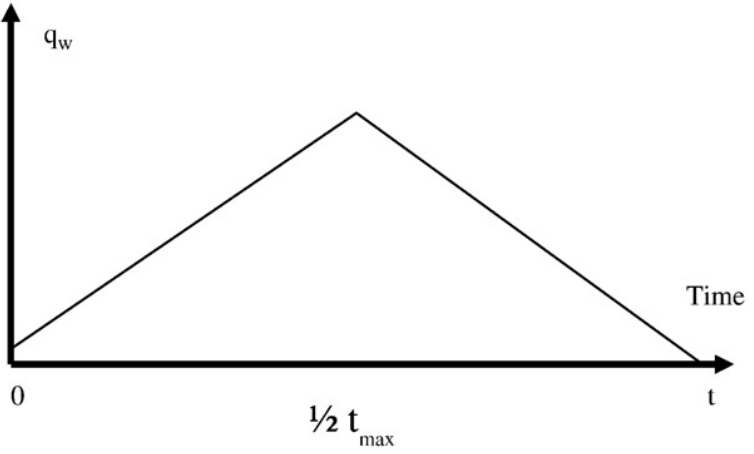

Fig. 5. Temporal evolution of water influx.

the upper part of the slope. In the lower part the water table is close to the surface.

\subsubsection{Constitutive law}

The elasto-plastic law for unsaturated soils Hiss- $\delta_{1 \text { unsat }}$ is used if not stated otherwise. Material parameters are given in Table 2.

\subsubsection{Initial conditions}

Initial conditions were generated by suddenly applying gravity. The calculations continued until steady state conditions were reached (all excess pore pressures dissipated). This state was used as the initial state for the test calculations.

\subsubsection{Varied parameters}

As detailed above, the following parameters could be of major importance in the initiation of debris flows:

Geometry: influence of the inclination angle of an infinite slope Material: its permeability and suction-saturation relation Constitutive law: influence of the overall material behaviour Initial conditions: variations in the initial water table

Boundary conditions: for varying hydrograms, showing different infiltration times as well as maximum values

These parameters will be varied in the following calculations to obtain an appreciation of their influence on the criteria discussed above

Table 2

Material parameters.

\begin{tabular}{|c|c|c|}
\hline Parameter & Value & Unit \\
\hline \multicolumn{3}{|l|}{ Solid skeleton } \\
\hline Grain density & 2650 & $\mathrm{~kg} / \mathrm{m}^{3}$ \\
\hline Porosity & 0.415 & \\
\hline Intrinsic permeability & $8 \cdot 10^{-12}$ & $\mathrm{~m}^{2}$ \\
\hline \multicolumn{3}{|l|}{ Fluid properties } \\
\hline Water density & 1000 & $\mathrm{~kg} / \mathrm{m}^{3}$ \\
\hline Water viscosity & $1.0 \cdot 10^{-3}$ & $\mathrm{~Pa} / \mathrm{s}$ \\
\hline Water compressibility & $4.5 \cdot 10^{-10}$ & $1 / \mathrm{Pa}$ \\
\hline Air density & 1.0 & $\mathrm{~kg} / \mathrm{m}^{3}$ \\
\hline Air viscosity & $1.8 \cdot 10^{-5}$ & $\mathrm{~Pa} / \mathrm{s}$ \\
\hline Air compressibility & $1.2 \cdot 10^{-5}$ & $1 / \mathrm{Pa}$ \\
\hline \multicolumn{3}{|l|}{ Elastic parameters } \\
\hline E-modulus & $43 \cdot 10^{6}$ & $\mathrm{~Pa}$ \\
\hline Poisson's ratio & 0.46 & \\
\hline \multicolumn{3}{|l|}{ Plastic parameters } \\
\hline$\gamma$ & 0.0425 & \\
\hline$\beta$ & 0.58 & \\
\hline$m$ & 3.1 & \\
\hline$\alpha_{m}$ & $2.59 \cdot 10^{-7}$ & \\
\hline$r$ & -15 & \\
\hline
\end{tabular}

and consequently on their influence on debris flow initiation. The latter will be assumed as soon as one of the above cited criteria is met.

\subsection{Influence of slope angle}

\subsubsection{Data}

The slope angle was varied and took the values $=20^{\circ}$ (Case 1$), 25^{\circ}$ (Case 2 ) and $30^{\circ}$ (Case 3 ). The other parameters of the simulation are given in Table 2. The calculations were carried out using a linear elastic material law.

\subsubsection{Results}

Figs. 6 and 7 show typical calculation results. In Fig. 6 the calculated displacements at time $t=500 \mathrm{~s}$ are presented. It can be seen that, for the three cases, the displacements are somewhat different from each other, especially in the upper part of the slope. Nevertheless, it is surprising that the maximum displacement was calculated for the lowest slope angle (Table 3). Almost no differences were found for the pore water pressures (Fig. 7). It seems as if this parameter, contrary to many statements found in the literature, was only of minor importance in the given context. This coincides with statements by Wieczorek et al. (1997) who correlated several topographic parameters to the debris flow initiation but found that no correlation existed with the slope angle.
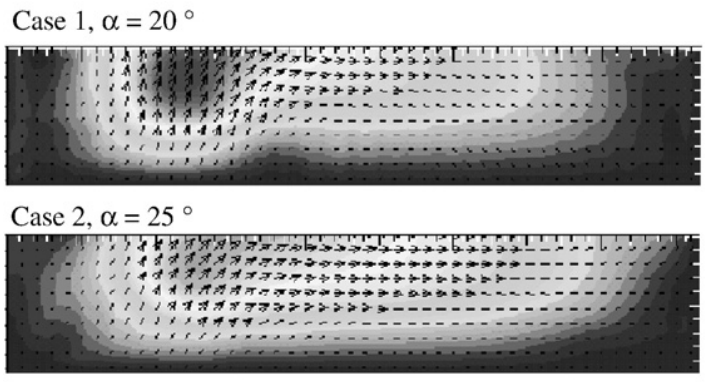

Case $3, \alpha=30^{\circ}$
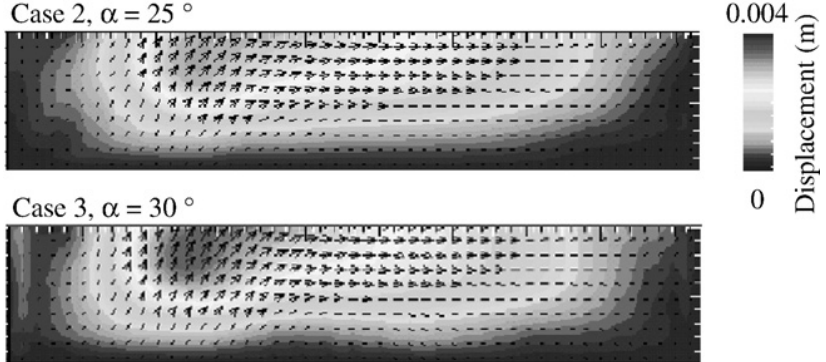

Fig. 6. Displacement for the three cases when $t=500 \mathrm{~s}$.

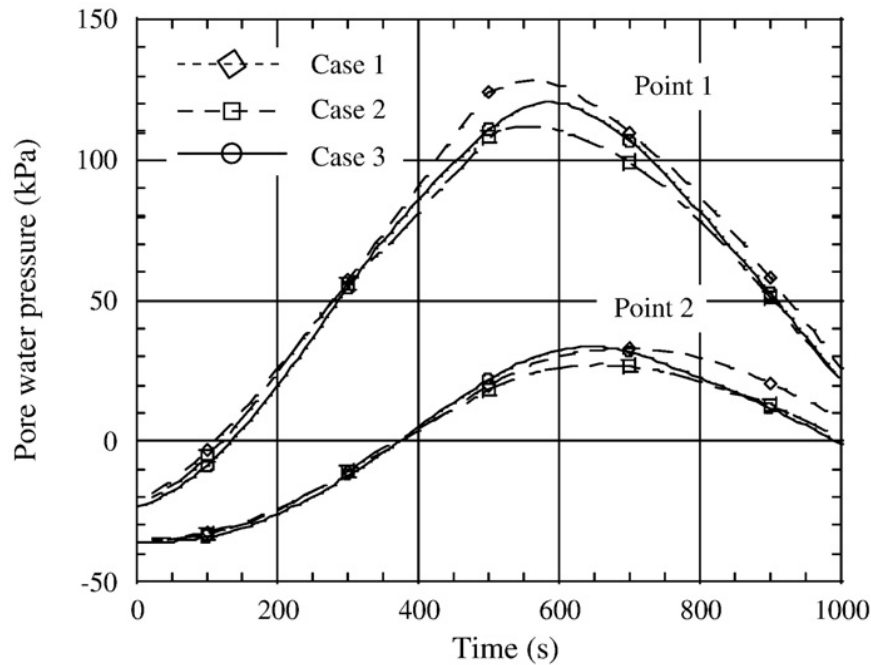

Fig. 7. Pore water pressure vs. time at the two points indicated in Fig. 2 for the three different cases. 
Table 3

Overview slope angle.

\begin{tabular}{ll}
\hline Parameter & Value \\
\hline Geometry & 1 \\
Angle $\alpha$ & Variable \\
Imposed flow & $q_{\mathrm{w}}=2 \cdot 10^{-4} \mathrm{~m}^{3} /\left(\mathrm{m}^{2} \mathrm{~s}\right)$ \\
Time scale & $t_{\mathrm{max}}=1000 \mathrm{~s}$ \\
Constitutive law & Linear elastic
\end{tabular}

Table 4

Overview permeability.

\begin{tabular}{ll}
\hline Parameter & Value \\
\hline Geometry & 2 \\
Slope angle $\alpha$ & $25^{\circ}$ \\
Imposed flow & $q_{\mathrm{w}}=2 \cdot 10^{-4} \mathrm{~m}^{3} /\left(\mathrm{m}^{2} \mathrm{~s}\right)$ \\
Time scale & $t_{\max }=1000 \mathrm{~s}$ \\
Constitutive law & Hiss- $\delta_{1 \text { unsat }}$ \\
\hline
\end{tabular}

\subsection{Influence of permeability}

\subsubsection{Dato}

Calculations for two different values for the geometric permeability $K$ were carried out: $K=8 \times 10^{-12} \mathrm{~m}^{2}$ (Case 1 ), and $K=8 \times 10^{-13} \mathrm{~m}^{2}$ (Case 2). Table 4 gives the other parameters used in the simulation.

\subsubsection{Results}

Typical results are shown in Figs. 8 and 9. The shear stress zone near the surface is more pronounced in Case 2, as can be seen in Fig. 8 . Also, the form of this zone of shear stress is significantly different in both cases. Moreover, it can be said that the overall reaction is much more intense but also much more localized for low permeability (Fig. 9). However, Case 1 developed a shear stress larger zone with higher maximal values, showing a steeper gradient at its limits. Such zones under tension will fail as cohesion vanishes, which is a mechanism that has been put forward by Sassa (1984).

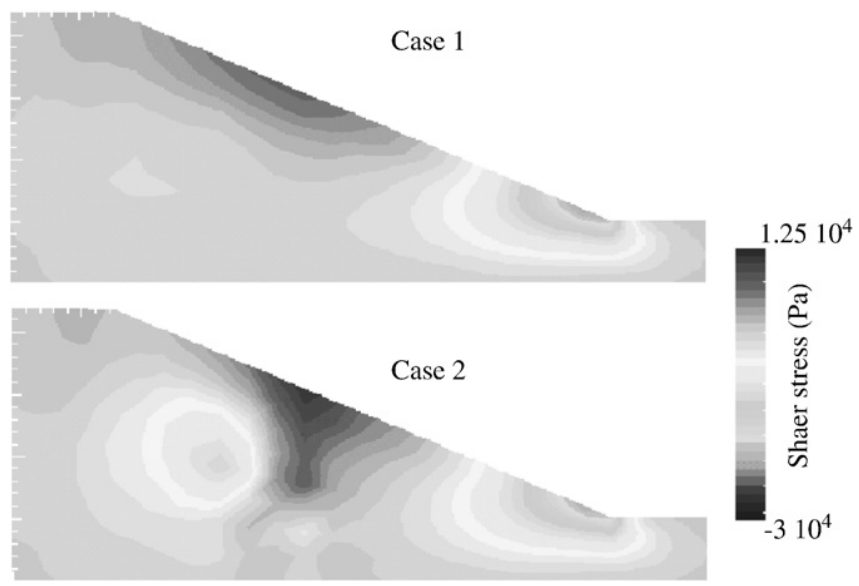

Fig. 8. Shear stress at time $t=500 \mathrm{~s}\left(1 / 2 t_{\max }\right)$.

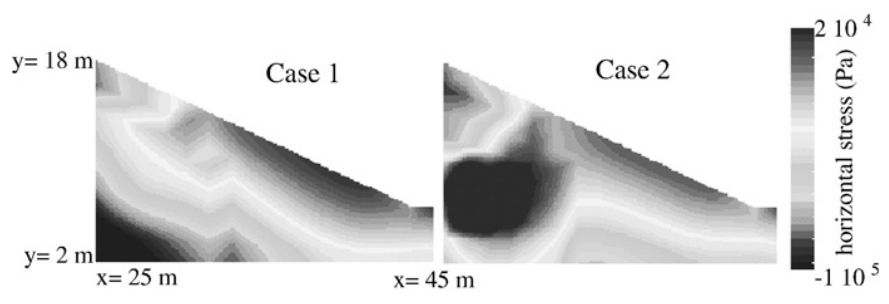

Fig. 9. Horizontal stress at time $t=500 \mathrm{~s}\left(1 / 2 t_{\max }\right)$ (detail).
Table 5

Overview suction-saturation relation.

\begin{tabular}{ll}
\hline Parameter & Value \\
\hline Geometry & 2 \\
Slope angle $\alpha$ & $25^{\circ}$ \\
Imposed flow & $q_{\mathrm{w}}=3.2 \cdot 10^{-5} \mathrm{~m}^{3} /(\mathrm{m} \mathrm{s})$ \\
Time scale & $t_{\mathrm{max}}=1000 \mathrm{~s}$ \\
Constitutive law & Hiss- $\delta_{1 \text { unsat }}$ \\
\hline
\end{tabular}

\subsection{Influence of the degree of saturation}

\subsubsection{Data}

A change in the suction-saturation relation causes a change in the degree of saturation for constant capillary pressures (Table 5). A steeper relation with a more rapid transition from the saturated to highly unsaturated state corresponds to a coarser material and a smoother transition and a high degree of saturation, even for relatively high capillary pressures, is characteristic of finer grained materials. Two suction-saturation relations were tested here. The corresponding relationships are represented graphically in Fig. 10.

\subsubsection{Results}

Figs. 11 and 12 illustrate the results obtained in this case. Once again, one notes that a lower degree of saturation (Case 1) coincides with a

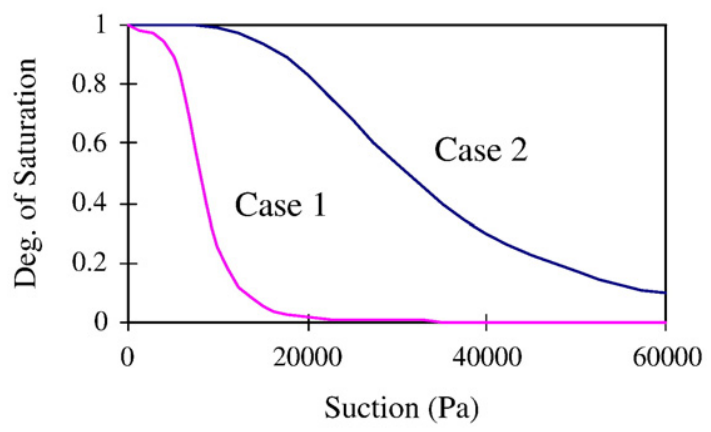

Fig. 10. Suction-saturation relation for Cases 1 and 2.

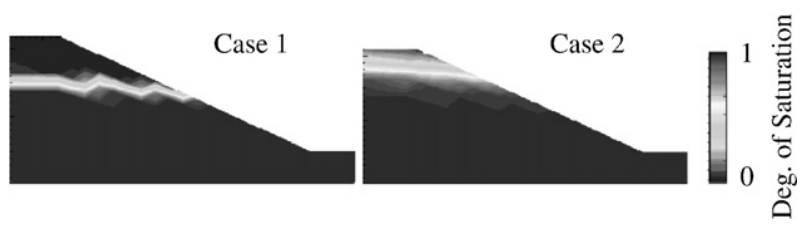

Fig. 11. Degree of saturation at time $t=0$ for both materials.

Case 1

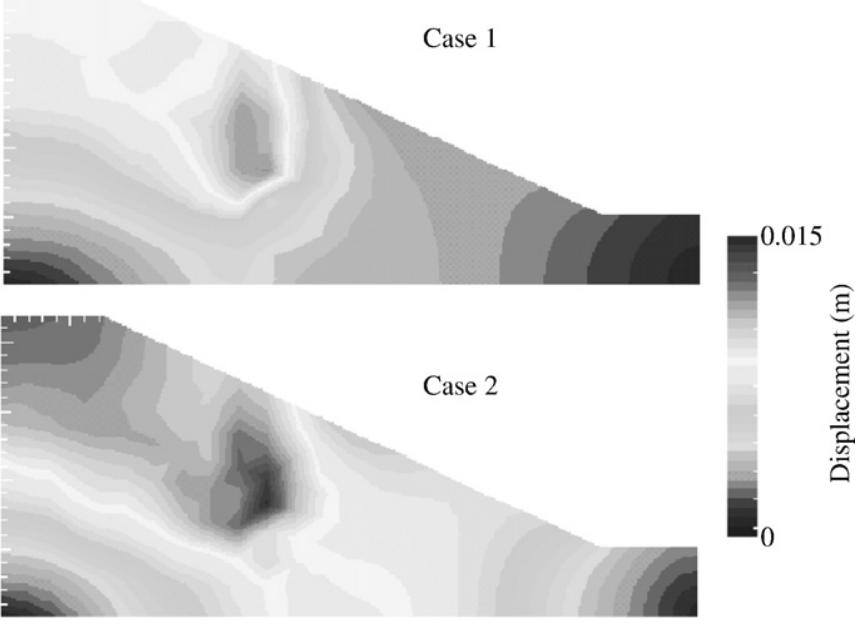

Fig. 12. Displacements at time $t=500 \mathrm{~s}\left(1 / 2 t_{\max }\right)$. 
Table 6

Overview constitutive law.

\begin{tabular}{ll}
\hline Parameter & Value \\
\hline Geometry & 2 \\
Slope angle $\alpha$ & $25^{\circ}$ \\
Imposed flow & $q_{\mathrm{w}}=2 \cdot 10^{-4} \mathrm{~m}^{3} /\left(\mathrm{m}^{2} \mathrm{~s}\right)$ \\
Time scale & $t_{\max }=1000 \mathrm{~s}$ \\
Constitutive law & Varied \\
\hline
\end{tabular}

more violent reaction and higher rigidity. The gradient of displacement at the limit of the zone of high displacement is much more pronounced, even if the displacement itself is more important in Case 2. In Case 2, the typical headscarp form is distinguishable at the slope surface.

\subsection{Influence of the soil behaviour}

\subsubsection{Data}

The influence of the soil type behaviour was examined by testing an elastic (Case 1) and an elasto-plastic case with the Hiss- $\delta_{1 \text { unsat }}$ model (Case 2). Table 6 gives the conditions of the simulations.

\subsubsection{Results}

Figs. 13 and 14 present the results of the two simulations. Fig. 14 shows a zone of concentrated displacement in the case of the elasto-

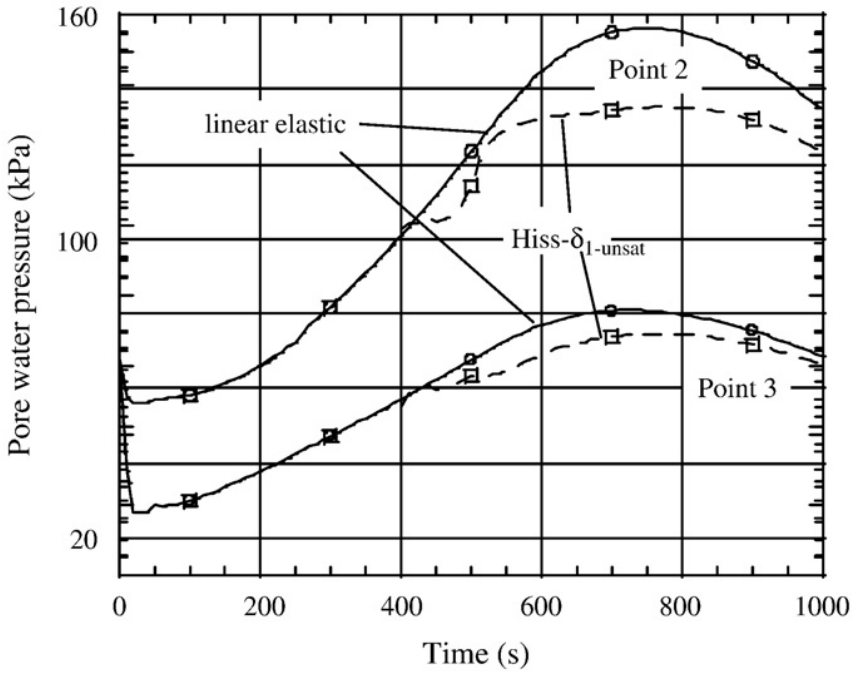

Fig. 13. Pore water pressures at points 2 and 3.
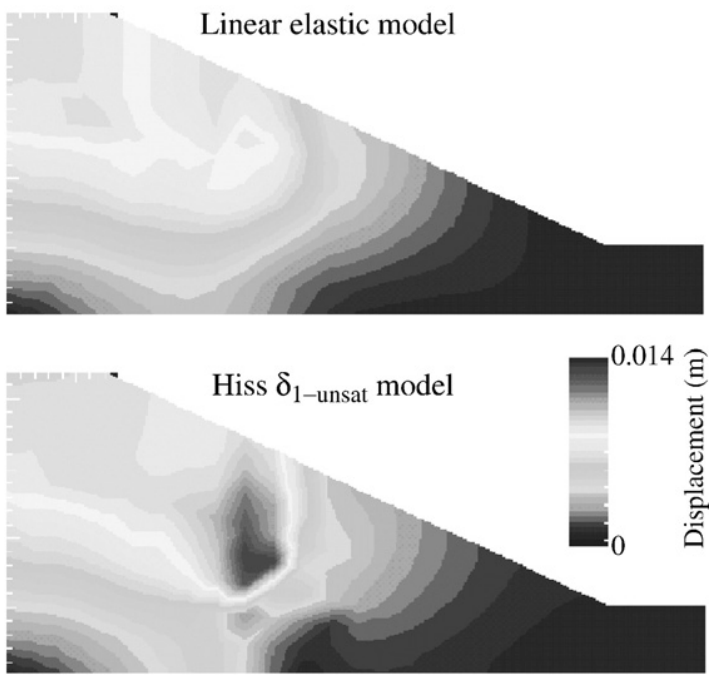

Fig. 14. Displacement at time $t=750 \mathrm{~s}$
Table 7

Overview water level.

\begin{tabular}{ll}
\hline Parameter & Value \\
\hline Geometry & 1 \\
Slope angle $\alpha$ & $25^{\circ}$ \\
Imposed pressure & $p^{\mathrm{w}}=10^{5} \mathrm{~Pa}$ \\
Time scale & Stationary \\
Constitutive law & Hiss- $\delta_{1 \text { unsat }}$
\end{tabular}

plastic model. This zone coincides with the plasticized zone. These features were not found using the elastic model. Divergence was also found in the calculated pore pressures. The higher pore water pressures were found in the elastic case; the divergence in the pressures started at the onset of plastification. This highlights the necessity of applying a material model that corresponds to the true material behaviour and takes into account governing parameters. The calculated reaction to the loading was completely different in both cases, and conclusions on slope stability and debris flow initiation will not be the same in the two cases; the displacement pattern is much more critical in the elasto-plastic case.

\subsection{Influence of water level}

4.6.1. Data

A commonly-cited influential factor in the context of debris flow initiation is the position of the water level and, consequently, the size of the unsaturated zone. To study this effect, the ground water table in geometry 1 was assumed to take the positions $0 \mathrm{~m}$ (Case 1), $5 \mathrm{~m}$ (Case 2) and $7 \mathrm{~m}$ (Case 3 ) below the surface (Table 7). The parameters used in the simulations are given in Table 9.

\subsubsection{Results}

Typical results are shown in Figs. 15, 16 and 17. The pore water pressures at time $t=500 \mathrm{~s}$ are presented in Fig. 15. They represent a stationary situation after the onset of loading (Fig. 17). It should be emphasized that maximum displacements were not observed for the saturated case (see Fig. 16) but for the case with the water level at $-5 \mathrm{~m}$. This coincides with the previous observation that a critical combination of undersaturation and loading leads to the most disadvantageous results.

\subsection{Influence of timing of the water supply \\ 4.7.1. Data}

Two different cases were studied. First, three calculations were made using the same maximum value of infiltration rate, but at different infiltration times $t_{\max }$ (Cases 1 to 3 ). In a second group, three calculations with different infiltration times and different maximum
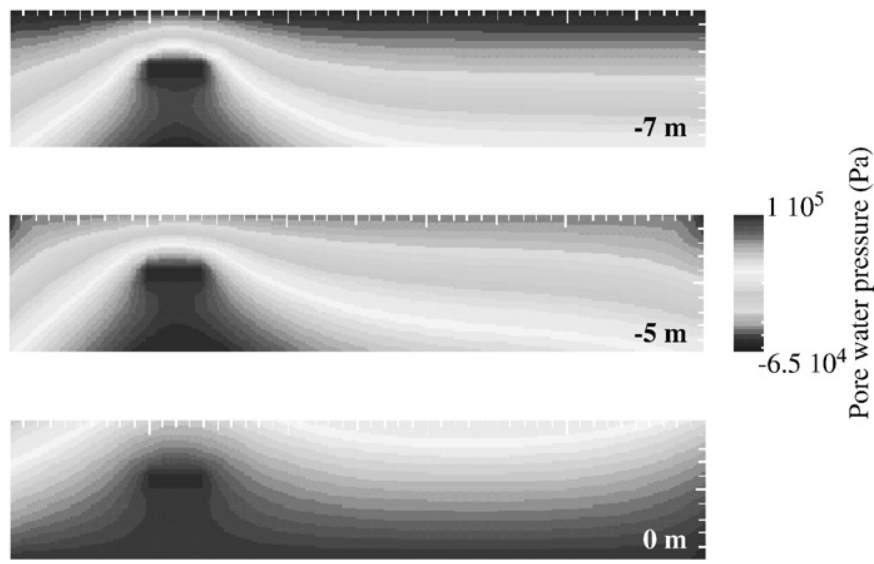

Fig. 15. Pore water pressures for Cases $1-3$ when $t=500$ s. 

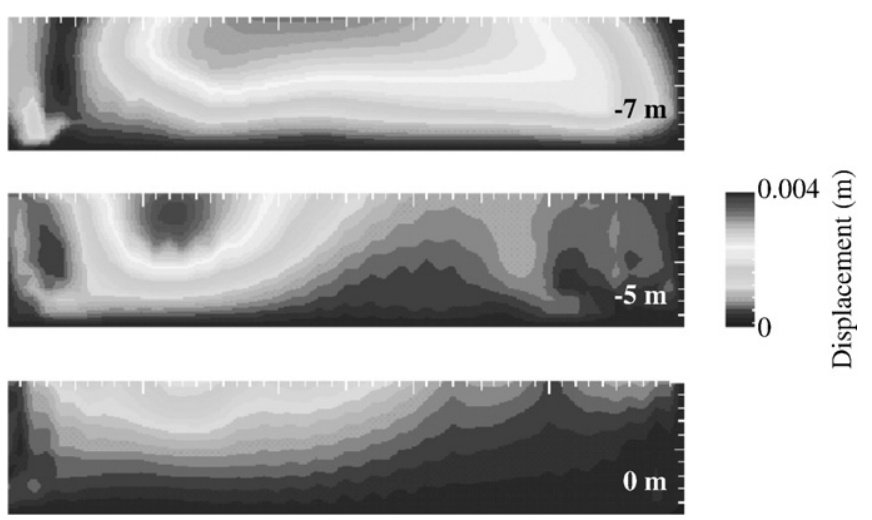

Fig. 16. Displacements for Cases 1 to 3 when $t=500$ s.

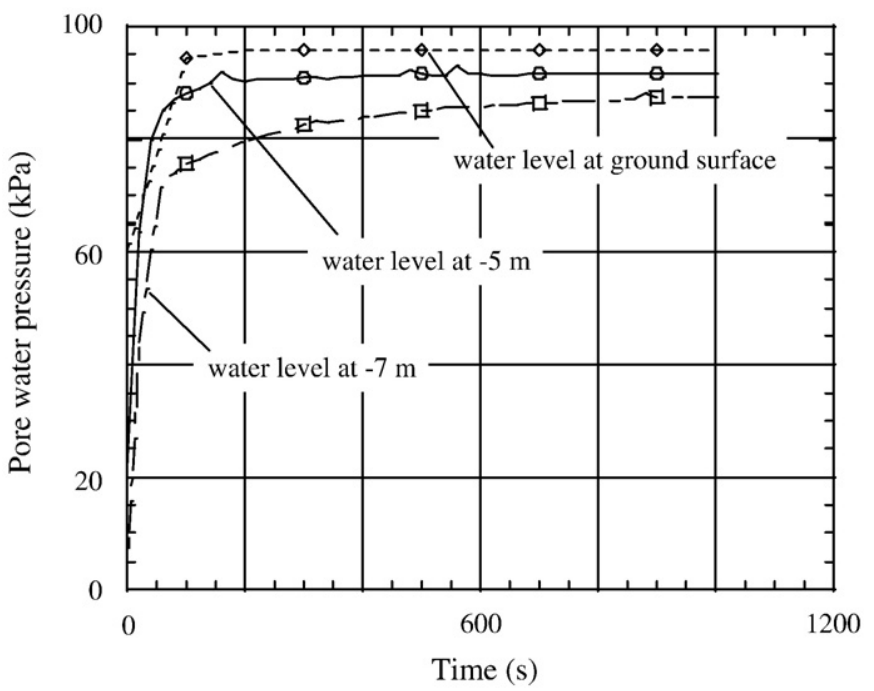

Fig. 17. Water pressure at point 2 vs. time.

values of infiltration rate were executed such that the overall infiltrated water quantity was the same in the three cases (Cases 4 to 6) (see Tables 8 and 9).

\subsubsection{Results}

One can see that Case 2 yields the most critical slope reaction, despite the fact that more water was supplied in Case 3 (Figs. 18 and 19); Case 2 results in higher pore pressures and larger displacements at the surface

Table 8

Overview water supply.

\begin{tabular}{ll}
\hline Parameter & Value \\
\hline Geometry & 1 \\
Slope angle $\alpha$ & $25^{\circ}$ \\
Imposed flow & $q_{\mathrm{w}}=2 \cdot 10^{-4} \mathrm{~m}^{3} /\left(\mathrm{m}^{2} \mathrm{~s}\right)$ \\
Time scale & Variable \\
Constitutive law & Hiss $\delta_{1 \text { unsat }}$ \\
\hline
\end{tabular}

Table 9

Varied parameters.

\begin{tabular}{ll}
\hline Case no & $t_{\max }$ \\
\hline 1 & $t_{\max }=1000 \mathrm{~s}$ \\
2 & $t_{\max }=10,000 \mathrm{~s}, q_{\mathrm{w}}=2 \cdot 10^{-4}$ \\
3 & $t_{\max }=100,000 \mathrm{~s}$ \\
4 & $t_{\max }=1000 \mathrm{~s}, q_{\mathrm{w}}=5 \cdot 10^{-4}$ \\
5 & $t_{\max }=10,000 \mathrm{~s}, q_{\mathrm{w}}=5 \cdot 10^{-5}$ \\
6 & $t_{\max }=100,000 \mathrm{~s}, q_{\mathrm{w}}=5 \cdot 10^{-6}$ \\
\hline
\end{tabular}

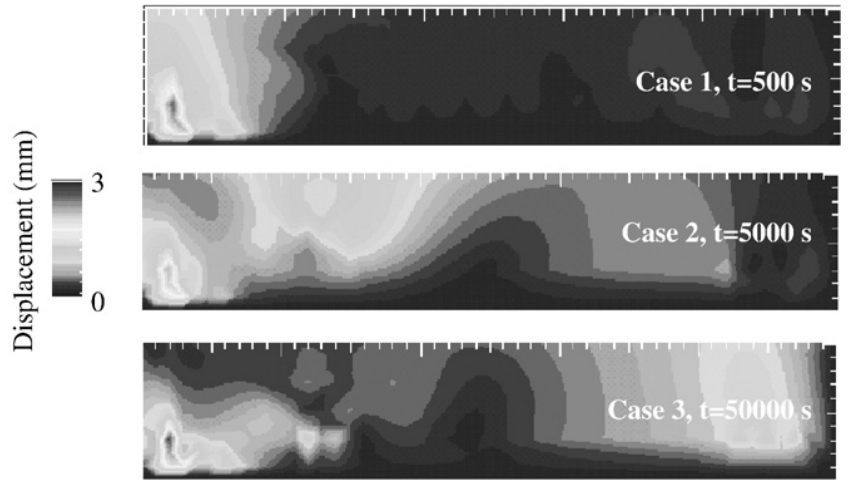

Fig. 18. Displacement at time $t=1 / 2 t_{\max }$ for Cases 1 to 3 .

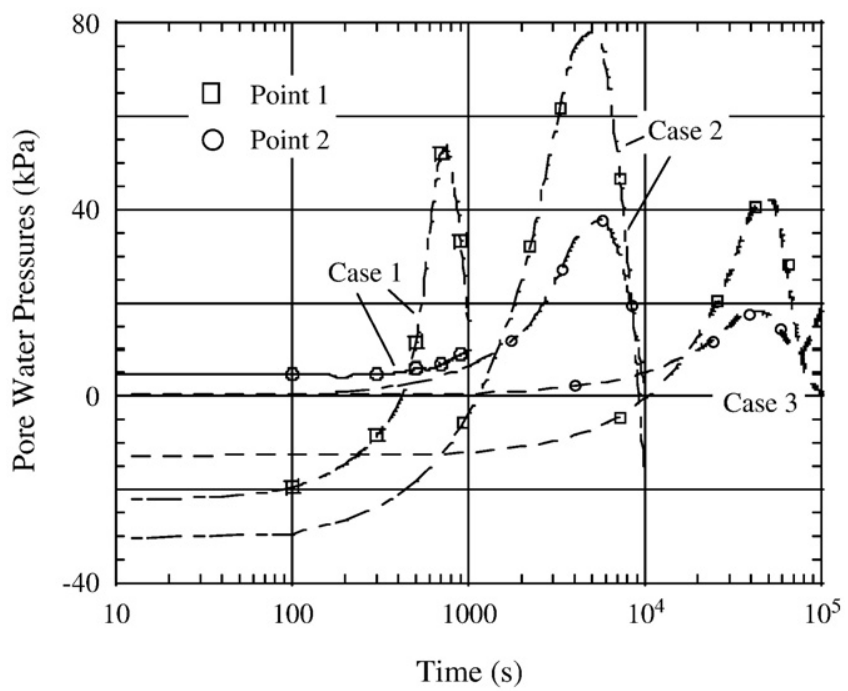

Fig. 19. Pore water pressure for Cases 1 to 3 vs. time at points 1 and $2^{1}$.

than all the other cases. If one assumes a relation between precipitation and water supply, as in the given example, the observations of intensityduration thresholds are partially confirmed: water supply over a short time range is, for the same intensity, less destabilizing than over a longer time. However, it is also found that Case 3 shows a reaction that is more similar to Case 1 than to Case 2. The successive saturation and consequent increase in permeability of the slope probably allows for a smoother reaction due to the (slow) water supply, even if the overall quantity is higher. This confirms the above observations once more.

The supply of an equal overall volume yields the results given in Fig. 20. The supplied overall volume was $1.2 \mathrm{~m}^{3}$ and was therefore $250 \%$ higher than the minimum volume of the first series (Cases 1 to 3 ). It is clear from the figure that the most rapid supply causes the most intense reaction. Apparently, the combination water supply/permeability is located in the critical range, and a pronounced slope reaction was caused.

\subsection{General discussion}

The influence of some of the most-cited parameters in relation with debris flow initiation has been studied. As could be expected, no single parameter that alone governs the phenomenon could be identified. It seems that a critical combination of permeability and water supply must occur to create instability. This has been found for several of the

${ }^{1}$ The different values of the water pressure at time $t=10 \mathrm{~s}$ are due to the temporal
variation in the water supply. The initial conditions at time $t=0$ (not represented in Fig. 19) are identical. 


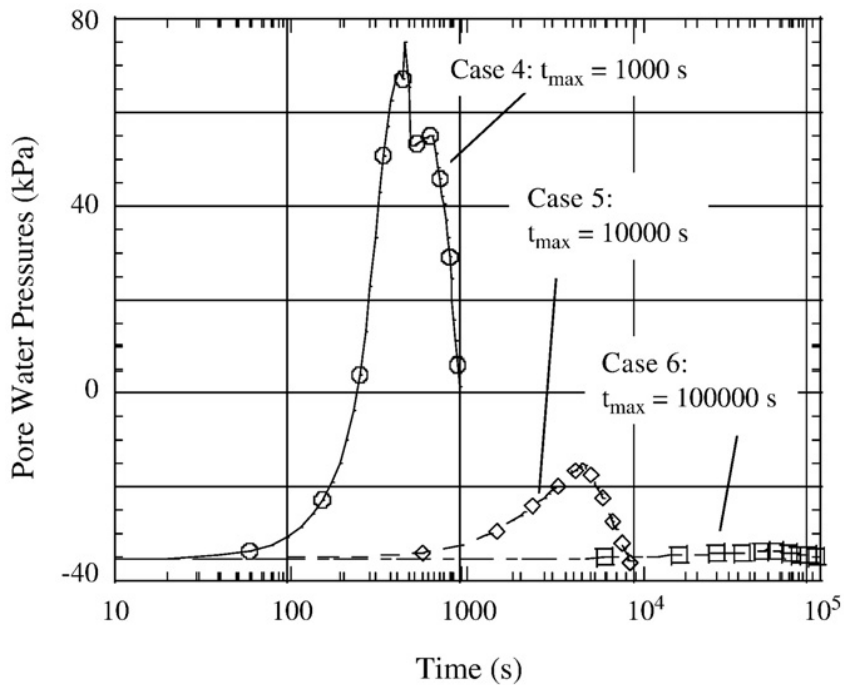

Fig. 20. Pore water pressure for the same supplied volume vs. time at point 1 (Cases 4 to 6 ).

calculations presented, independent of the way the relation changed. For example, different materials expressed by the geometric permeability or the suction-saturation relation, the degree of saturation, the water level or the intensity of the water supply can all cause instability. If less water is supplied over a short period, the unsaturated soil may easily absorb the water. If large quantities of water are supplied over a long time span with a relatively slow increase in the supply rate, the unsaturated soil slowly becomes saturated; this yields a water permeability increase and the supplied water can be drained away more easily. In an intermediate situation, where water is supplied too rapidly to allow for saturation and drainage and where the supplied quantity exceeds the storage capabilities of the soil, high pore pressures develop and the slope is prone to instability.

This observation presents no contradiction with existing models for debris flow initiation in slopes. Intensity-duration thresholds partly cover the above observations (Caine, 1980) and correlations with hydraulic quantities, such as the acceleration of the water level movement, support the above statements. Additionally, correlations between topographic parameters and initiation, such as slope geometry and contributing surfaces, can be understood in that way.

The above results may partially explain the problems encountered by Iverson et al. (1997) in the calculation of their experiments: they did not consider coupling or transient behaviour, which are two points that were found to be essential. The important role of pore pressure is confirmed; the stress paths stated by Anderson and Sitar (1995) or Lee et al. (1988) are reproduced (see also Klubertanz, 1999). The observations and conclusions by Sassa (Sassa et al., 1980, Sassa, 1984, ) are confirmed insofar as the destabilizing effect of a loss of suction is clearly visible.

\section{Conclusions}

A coupled solid-fluid hydromechanical model for unsaturated porous media was applied for debris flow initiation problems. It was shown that the model is applicable and able to provide indications for slope instabilities. It was found that the slope angle is only of minor importance when the internal water supply is the driving mechanism. The transient behaviour of the water supply seems to be a critical parameter; the time evolution of the infiltration flux seems to be more critical than the maximum value of the water supply. This may be due to a critical combination of the parameters supply and permeability. It seems, therefore, that transient behaviour should not be disregarded in studying debris flow initiation and that water supply should be correlated with the permeability of the soil as a function of its actual degree of saturation.
Based on those results, some conclusions may be drawn. Concerning the simulation of debris flow initiation in slopes, it should be noted that

- a coupled three-phase approach is necessary

- advanced material models, including mechanical and hydric hardening, should be used.

This modelling approach meets all the requirements mentioned above and has been shown to be applicable and yield good and innovative results.

With regard to debris flow initiation, the role of the hydraulic behaviour of the soil and in particular the transient-unsaturated behaviour is found to be dominant. If one wants to identify one governing parameter, in spite of the evident complexity of the process, this might be the material permeability. This parameter is subject to variations due to the degree of saturation or other effects and has a relationship with the water supply. However, the time-dependent water supply must be considered.

To validate the application of the above model with real debris flow situation may not be possible because, to the knowledge of the authors, there is no instrumented site or large-scale experiment that has the potential to provide the necessary data.

\section{Acknowledgements}

This research was funded in part by the Board of Directors of the Swiss Federal Institutes of Technology (Debris Flow project).

\section{Appendix A}

The matrices in Eq. (5) given in detail using standard finite elements notation:

$$
\begin{aligned}
& \mathbf{M}^{\mathrm{w}}=\int_{\Omega} n\left(\frac{\partial S^{\mathrm{w}}}{\partial s}+\frac{S^{\mathrm{w}}}{\rho^{\mathrm{w}}} \frac{\partial \rho^{\mathrm{w}}}{\partial p^{\mathrm{w}}}\right) N^{\mathrm{T}} N d \Omega \\
& \mathbf{M}^{\mathrm{a}}=\int_{\Omega} n\left(\frac{\partial S^{\mathrm{w}}}{\partial s}+\frac{1-S^{\mathrm{w}}}{\rho^{\mathrm{a}}} \frac{\partial \rho^{\mathrm{a}}}{\partial p^{\mathrm{a}}}\right) N^{\mathrm{T}} N d \Omega \\
& \mathbf{H}^{\mathrm{w}}=\int_{\Omega} S^{\mathrm{w}} K^{\mathrm{w}} \nabla N^{\mathrm{T}} \nabla N d \Omega \\
& \mathbf{H}^{\mathrm{a}}=\int_{\Omega}\left(1-S^{\mathrm{w}}\right) K^{\mathrm{a}} \nabla N^{\mathrm{T}} \nabla N d \Omega \\
& \mathbf{N}^{\mathrm{aw}}=\int_{\Omega} n \frac{\partial S^{\mathrm{w}}}{\partial s} N^{\mathrm{T}} N d \Omega \\
& \mathbf{N}^{\mathrm{wa}}=\int_{\Omega} n \frac{\partial S^{\mathrm{w}}}{\partial s} N^{\mathrm{T}} N d \Omega
\end{aligned}
$$

\section{References}

Anderson, S.A., Sitar, N., 1991. Influence of stress path on soil strength parameters and analysis of rainfall induced slope failures. Symp. Eng. Geol. Geotech. Eng. 27 (21-1), 21-26.

Anderson, S.A., Sitar, N., 1995. Analysis of rainfall-induced debris flows. J. Geotech. Eng., ASCE 121 (7), 544-552.

Bishop, A.W., 1959. The principle of effective stress. Tecnisk Ukeblad 39, 859-863.

Blijenberg, H.M., 1993. Results of debris flow investigations on the recent time scale. Temporal Occurrence and Forcasting of Landslides in the European Community, Contract no. 900025, Direction des Transports, de l'Energie et des Eaux du Canton de Berne (DTEE), pp. 609-650.

Buchanan, P., Savigny, K., 1990. Factors controlling debris avalanche initiation. Can. Geotech. J. 27, 659-675.

Budhu, M., 1995. Seepage induced slope failures on sandbars in the Grand Canyon J. Geotech. Eng. 121 (8), 601-609.

Caine, N., 1980. The rainfall intensity-duration control of shallow landslides and debris flows. Geog. Ann. A62, 23-27. 
Cojean, R., 1994. Role of groundwater as a triggering factor for landslides and debris flow. Proc. Int. workshop on flood and inondations related to large earth movements. Trento, Italy. A13-1, A13-19.

Cojean, R., Staub, I., 1998. Mécanismes d'initiation des laves torrentielles dans les Alpes francaises. 8th International IAEG Congress. Balkema, pp. 2075-2082.

Costa, J.E., 1984. Physical geomorphology of debris flows. In: Costa, J.E., Fleisher, P.J. (Eds.), Developments and Applications of Geomorphology, pp. 268-317.

Desai, C.S., Sharma, K.G., Wathugala, G.W., Rigby, P.B., 1991. Implementation of hierarchical single surface $\delta_{0}$ and $\delta_{1}$ models in finite element procedure. Int. J. Num. Anal. Meth. Geomech. 15, 649-680.

Dysli, M., 1998. Loss of bearing capacity of road during thaw and debris flows in mountain permafrost: the same phenomenon. Permafrost and Actions of Natural and Artificial Cooling. Colloquium of the "Institut du Froid", pp. 1-8.

Eckersly, D., 1990. Instrumented laboratory flowslides. Géotechnique 40 (3), 489-502.

Ellen, S.D., Fleming, R.W., 1987. Mobilization of debris flows from soil slips, San Francisco Bay Region, California, debris flows/avalanches: process, recognition and mitigation. Rev. Eng. Geol. Geol. Soc. Am. 7, 31-40.

Fannin, R.J., Rollenson, T.P., 1993. Debris flow: some physical characteristics and behaviour. Can. Geotech. J. 30, 71-81.

Geiser, F., Laloui, L., Vulliet, L., 2000. Modelling the behaviour of unsaturated soils. In: Tarantino, A., Maucuso, C. (Eds.), Proceedings "Unsaturated Soils: Experimental Evidence and Theoretical Approaches". Balkema, pp. 155-176.

Griffiths, P.G., Webb, R.H., Melis, T.S., 1997. Initiation of debris flows in tributaries of the Colorado River in Grand Canyon, Arizona. 1st International Conference on Debris Flow Hazards Mitigation: Mechanics, Prediction, and Assessment, San Francisco, CA, USA, pp. 12-20.

Haneberg, W.C., 1991. Observation and analysis of pore pressure fluctuations in a thin colluvium landslide complex near Cincinnati, Ohio. Eng. Geol. 31, 159-184

Haneberg, W.C., 1995. Groundwater flow and the stability of heterogeneous infinite slopes underlain by impervious substrata. Rev. Eng. Geol. X, 63-77.

Harp, E.L., Jibson, R.W., 1996. Inventory of landslides triggered by the 1994 Northridge, California earthquake. U.S. Geol. Surv.,Open-File Rep. 95-213.

Hassanizadeh, M., Gray, W.G., 1979a. General conservation equations for multi-phase systems: 1. Averaging procedure. Adv. Water Resources 2, 131-144.

Hassanizadeh, M., Gray, W.G, 1979b. General conservation equations for multi-phase systems: 2. Mass, momenta, energy and entropy equations. Adv. Water Ressources $2,191-203$

Iverson, R.M., 1997. The physics of debris flows. Rev. Geophys. 35 (3), 245-296.

Iverson, R.M., Reid, M.E., 1992. Gravity-driven groundwater flow and slope failure potential: 2. Effects on slope morphology, material properties and hydraulic heterogeneity. Water Res. Research 28, 939-950.

Iverson, R.M., Reid, M.E., Lahusen, R.G., 1997. Debris flow mobilization from landslides. Annu. Rev. Earth Planet. Sci. 25, 85-138.

Johnson, A.M., Rahn, P.H., 1970. Mobilization of debris flow. Z Geomorphologie, Suppl.bd. 9, 168-186.

Johnson, A.M., Rodine, J.R., 1984. Debris flow. In: Brunsden, D., Prior, D.B. (Eds.), Slope Instability, pp. 257-361.

Johnson, K.A., Sitar, N., 1990. Hydrologic conditions leading to debris flow initiation. Can. Geotech. J. 27, 789-801.

Klubertanz, G. 1999. "Zur hydromechanischen Kopplung in dreiphasigen porösen Medien: Modellbildung und Anwendung auf die Auslösung von Murgängen", PhD Thesis no. 2027 Swiss Federal Institute of Technology, EPFL, Switzerland.

Klubertanz, G., Laloui, L., Vulliet, L., 1997. Numerical modeling of the hydro-mechanical behaviour of unsaturated porous media. NAFEMS World Congress 1997, Stuttgart. 1302-1313.

Klubertanz, G., Laloui, L., Vulliet, L., 2000. Parameters governing debris flow initiation. In: Wieczorek, G.F., Naeser, N.D. (Eds.), Debris-Flow Hazards Mitigation: Mechanics, Prediction and Assessment. Balkema, pp. 3-79.

Lade, P.V., 1993. Initiation of static instability in the submarine Neklerk beam. Can. Geotech. J. 30, 895-904.

Laloui, L., Klubertanz, G., Vulliet, L., 2003. Solid-liquid-air coupling in multiphase porous media. Int. J. Numer. Anal. Methods geomech. volume 27 (issue 3), 183-206.

Laloui, L., Nuth, M., 2009. On the use of the generalised effective stress in the constitutive modelling of unsaturated soils. Comput. Geotechnics Vol. 36 (1-2), 20-23. doi:10.1016/j.compgeo.2008.03.002.

Lee, H.J., Ellen, S.D., Kayen, R.E., 1988. Predicting transformation of shallow landslides into high-speed debris flows. Proc. V Int. Symp. Landslides, Lausanne 1, 713-718.
Meyer, G.A., Wells, S.G., 1997. Fire-related sedimentation events on alluvial fans, Yellowstone National Park, USA. J. Sediment. Res., sect. A sediment. Pet. Proc. 67 (5) 776-791.

Mortara, G., Dutto, F., Godone, F., 1995. Failures induced by heavy rainfall in proglacial environment: the downcutting of neoglacial moraine of Mulinet Glacier (Upper Valle di Lanzo, Western Alps). Geogr. Fis. Din. Quat. 18 (2), 295-304.

Morton, D.M., Cambell, R.H., 1973. Mudflows at Rightwood, Southern California, Spring 1969. Quart. J. Eng. Geol. 7, 377-384.

Nuth, M., Laloui, L., 2008. Effective stress concept in unsaturated soils: clarification and validation of a unified framework. Int. J. Numer. Anal. Methods Geomech. 32 (7), 771-801.

Okimura, T., 1983. Rapid mass movement and ground water level movement. Z. Geomorphol.,Suppl.bd. 46, 35-54.

Reid, M.E., Nielsen, H.P., Dreiss, S.J., 1988. Hydrologic factors triggering a shallow hillslope failure. Bull. Assoc. Eng. Geol. 25, 349-361.

Reid, M.E., Iverson, R.M., 1992. Gravity-driven groundwater flow and slope failure potential: 1. Elastic effective stress model. Water Res. Research 28, 925-938.

Rickenmann, D., Zimmermann, M., 1993. The 1987 debris flows in Switzerland: documentation and analysis. Geomorphology 8, 175-189.

Rickenmann, D., 1995. Beurteilung von Murgaengen. Schweiz. Ing. Archit.SIA 48, 1104-1108.

Rösli, U., Schindler, C., 1990. Debris Flow 1987 in Switzerland: Geological and Hydrogeological Aspects. Hydrology in Mountainous Regions, Symposion IAHS, Lausanne, pp. 379-386.

Rovina, V., 1995. Rittigraben, St. Niklaus, Rovina + Partner AG, interner Bericht

Sassa, K., 1984. The mechanism starting liquefied landslides and debris flows. IV Int. Symp Landslides, Toronto, Canada 2, 349-354.

Sassa, K., 1988. Special lecture: geotechnical model for the motion of landslides. V Int. Symp Landslides, Lausanne, Switzerland 1, 37-55.

Sassa, K., Takei, A., Kobashi, S., 1980. Landslides triggered by vertical subsidences. Int. Symp Landslides, New Delhi 1980, 49-54.

Schrefler, B.A. 1984. The finite element method in soil consolidation (with applications to surface subsidence). Ph. D. Thesis, University College of Swansea, C/Ph/76/84.

Schrefler, B.A., Simoni, L., Xikui, Li, Zienkiewicz, O.C., 1990. Mechanics of partially saturated porous media. In: Desai, C.S., Gioda, G. (Eds.), Numerical Methods and Constitutive Modelling in Geomaterials, pp. 169-209.

Seker, E. 1983. Etude de la déformation d'un massif de sol non saturé. PhD thesis n ${ }^{183}$, Swiss Federal Institute of Technology, EPFL, Switzerland.

Service hydrologique et géologique national. 1995. Nant du Pissot, Commune de Villeneuve (VD), Laves torrentielles du 13./14. aout 1995, Documentation de l'événement, Berne.

Statham, I., 1976. Debris flows on vegetated screes in the Black Mountain, Carmathenshire. Earth Surf. Processes 1,173-180.

Suwa, H., 1989. Field observation of debris flow. Proceedings of the Japan-China (Taipei), Joint Seminar on Natural Hazard Mitigation, Kyoto, Japan, pp. 343-352.

Takahashi, T., 1980. Evaluation of the factors relevant to the initiation of debris flow. Proc. Int. Symp. on Landslides, New Dehli 136-140.

Takahashi, T., 1981. Debris flow. Ann. Rev. Fluid Mech. 13, 57-77.

Takahashi, T., 1991. Debris flow. IAHR Monograph Series. A.A. Balkema, Rotterdam.

Tognacca, C. 1999. Beitrag zur Untersuchung der Entstehungsmechanismen von Murgängen. Doktorarbeit, VAW Zürich, ETH Zürich.

Tognacca, C., Bezzola, G.R., 1997. Debris flow initiation by channel-bed failure. 1st International Conference on Debris Flow Hazards Mitigation: Mechanics, Prediction, and Assessment, San Francisco, CA, USA, pp. 44-53.

Wieczorek, G.F., Mandrone, G., DeCola, L., 1997. Influence of hillslope shape on debrisflow initiation. 1st International Conference on Debris Flow Hazards Mitigation Mechanics, Prediction, and Assessment, San Francisco, CA, USA, pp. 21-31.

Williams, G.P., Guy, H.P, 1973. Erosional and depositional aspects of hurricane Camille in Virginia, 1969. US Geological Survey Professional Paper, p. 804.

Zimmermann, M., 1994. Murgänge im Dorfbach von Randa (VS). Beurteilung von Massnahmen, Wasser, Energie, Luft - eau, énergie, air, 1/2 (86. Jahrgang, 1994, pp. 17-21.

Zimmermann, M., Häberli, W., 1992. Climatic change and debris flow activity in highmountain areas; a case study in the Swiss Alps. European Conference on Landscape Ecological Impact of Climatic Change. Federal Republic of Germany, CremlingenDestedt. 